\title{
70. Blockade of Transmitter Release by a Synthetic Venom Peptide, w-Conotoxin
}

\author{
By Koh-ichi Enomoto,*) Kazuya Sano,**) Yuzo Shibuya,***) \\ and Takashi MAENo*) \\ (Communicated by Yasuji Katsuki, M. J. A., Sept. 12, 1986)
}

Conotoxin GVIA ( $\omega$-conotoxin) is a venom peptide purified from the fisheating marine molluse Conus geographus, $\left.{ }^{91}, 10\right)$ and its amino acid sequence has already been described.9) The effect of $\omega$-conotoxin has been shown to be due to its inhibition of the $\mathrm{Ca}^{2+}$ influx of the presynaptic nerve terminal.5) Recently, this polypeptide toxin was synthesized by Peptide Institute, Protein Research Foundation (Minoo, Japan). Since there is a possibility that the tertiary structures of synthetic and natural $\omega$-conotoxin are different, it is worth to check the potency of the synthetic $\omega$-conotoxin. In the present investigation, we studied the effects of synthetic $\omega$-conotoxin on the frog neuromuscular junction, and observed that the synthetic toxin also has strong inhibitory effects on the transmitter release as does purified natural toxin.

Cutaneus pectoris and sartorius nerve-muscle preparations isolated from the frogs, Rana catesbeiana and Rana nigromaculata were used. The conventional intracellular recording technique was employed for measurements of the endplate potential (EPP). A digital memory/laboratory microcomputer was routinely used for analysis of the mean quantal content $(m)$ and quantal height $(q)$, by means of the variance method. ${ }^{3)}$ For analysis of $m$ and $q$, the transmitter release was reduced by adding $2 \mathrm{mM} \mathrm{MgCl}_{2}$. Alternatively, $d$-tubocurarine was used for measurement of the time course of $\omega$-conotoxin block. The concentrations of $d$-tubocurarine were 0.8-1.6, 3.8-6.4, 6.4 and 8.0-9.9 $\mu \mathrm{M}$ for $0.9,2.7,6.0$ and $10 \mathrm{mM}$ $\mathrm{Ca}^{2+}$ Ringer's solution, respectively.

For measurements of directly evoked EPP, muscle preparations were exposed to $1 \mu \mathrm{M}$ tetrodotoxin. The EPP was triggered by application of an electrical pulse with an extracellular electrode located close to the junction. ${ }^{4)}$ The diameter of the extracellular electrode was approximately $50 \mu \mathrm{m}$. The directly evoked EPP was recorded using the intracellular electrode.

The Ringer's solution used consisted of $(\mathrm{mM}): \mathrm{NaCl} 115, \mathrm{KCl} 2.5$ and $\mathrm{CaCl}_{2}$ 0.9 , unless otherwise noted. $\mathrm{pH}$ was adjusted to 7.4 using $2 \mathrm{mM} \mathrm{HEPES} / \mathrm{NaOH}$ buffer. Phenol red $\left(5 \times 10^{-4} \%\right)$ was used as an aid for adjusting the $\mathrm{pH}$ of the Ringer's solution. Synthetic $\omega$-conotoxin was supplied by Peptide Institute, Protein Research Foundation (Minoo, Japan). Other drugs were obtained from commercial suppliers.

Within a $\mathrm{Ca}^{2+}$ concentration range from 0.9 to $2.7 \mathrm{mM}$, the amplitude of Japan.

*) Department of Physiology, Shimane Medical University, Izumo, Shimane 693,

**) Department of Internal Medicine, Shimane Medical University, Izumo, Shimane 693, Japan.

***) Department of Ophthalmology, Shimane Medical University, Izumo, Shimane 693, Japan. 
the EPP was dramatically reduced by $40 \mathrm{nM} \omega$-conotoxin (Fig. 1A). The reaction was completely irreversible, since ther $€$ was no sign of recovery even after $5 \mathrm{hr}$ of washout. However, the effects of $\omega$-conotoxin changed with the extracellular $\mathrm{Ca}^{2+}$ concentration. The rate of reduction of the EPP decreased in $6 \mathrm{mM} \mathrm{Ca}^{2+}$ Ringer's solution until finally, at $10 \mathrm{mM} \mathrm{Ca}^{2+}$, there was no apparent reduction of EPP (Fig. 1A).
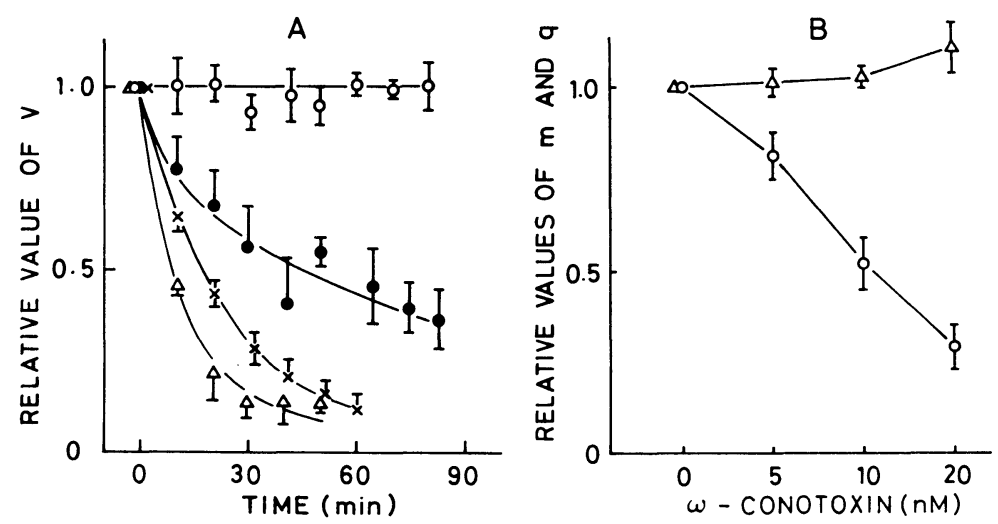

Fig. 1. A, B: Effects of $\omega$-conotoxin on the peak height of the endplate potential (EPP), mean quantal content $(m)$ and quantal height $(q)$. Values were normalized by control. The vertical bar shows standard error. The exchange of bathing solution was completed within 2-3 min. A : Averages of the time course of inhibition of the EPP by $\omega$-conotoxin. $V$, amplitude of the EPP. The concentration of $\omega$-conotoxin was $40 \mathrm{nM}$. The external $\mathrm{Ca}^{2+}$ concentrations were 0.9 , 2.7, 6 and $10 \mathrm{mM}$ for triangles, crosses, filled circles and open circles, respectively. Values are averages of 4 experiments for each concentrations of $\mathrm{Ca}^{2+}$. B: Dosedependent inhibition of mean quantal content $(m)$ by $\omega$-conotoxin. $m$ and $q$ were measured $30 \mathrm{~min}$ after perfusion of a given concentration of $\omega$-conotoxin. Values are averages of 7-10 experiments. Open circles, $m$; open triangles, $q$. The slight increase of $q$ by $20 \mathrm{nM} \omega$-conotoxin was due to a decrease in $\mathrm{S} / \mathrm{N}$ ratio.

Statistical analysis revealed that the decrease in the peak height of the EPP was due to the reduction of $m$; the quantal height remained unaffected (Fig. 1B). $\omega$-Conotoxin lacked any postsynaptic effects, since the muscle membrane potential and the peak height of the miniature endplate potential unaltered by $\omega$-conotoxin (data not shown). In addition, $\omega$-conotoxin had no effect on the wave form of the focally recorded presynaptic action potentialis) (and our unpublished data).

All of the above findings and the data reported by Kerr and Yoshikami ${ }^{5}$ ) indicate that synthesized $\omega$-conotoxin has completely the same effects as the natural toxin, and is a blocker of the presynaptic $\mathrm{Ca}^{2+}$ channel. To confirm this possibility, the effects of $\omega$-conotoxin on the directly evoked EPP were studied. In the presence of tetrodotoxin, it is possible to stimulate the voltage-dependent $\mathrm{Ca}^{2+}$ channels in the membrane of the presynaptic nerve terminal without generating the action potential.4) The finding that $40 \mathrm{nM} \omega$-conotoxin decreased and finally abolished the directly evoked EPP (Fig. 2), supported the idea that $\omega$-conotoxin blocks the voltage-dependent $\mathrm{Ca}^{2+}$ channel in the presynaptic nerve membrane. 


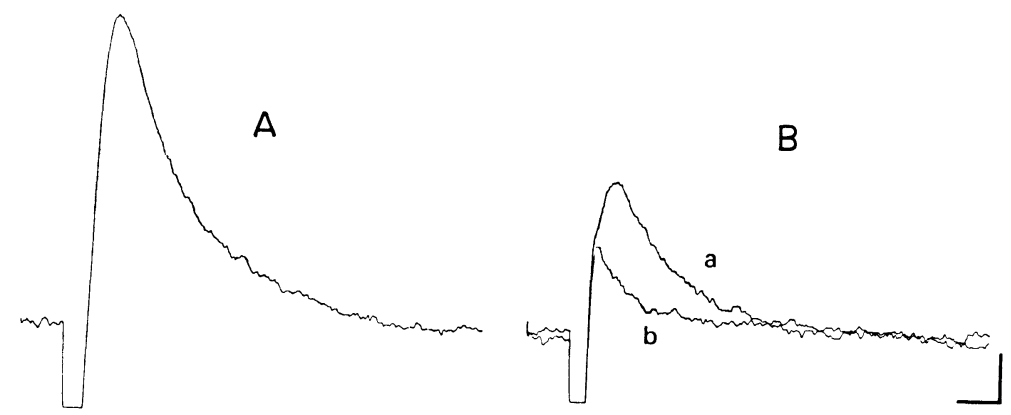

Fig. 2. Effects of $\omega$-conotoxin on the directly evoked endplate potential (EPP). The nerve action potential was blocked with $1 \mu \mathrm{M}$ tetrodotoxin. A: Control. B: $30 \mathrm{~min}$ after perfusion of $40 \mathrm{nM}$ w-conotoxin. a, evoked EPP depressed with the toxin; b, stimulus artifact only. Stimulation was $2 \mu \mathrm{A}, 0.5 \mathrm{msec}$. Records $\mathrm{A}$ and $B$ are from the same endplate. Resting membrane potentials were -71 and -88 $\mathrm{mV}$ for $\mathrm{A}$ and $\mathrm{B}$, respectively. Similar results were obtained in 4 other experiments. Calibrations, $2 \mathrm{msec}$ and $0.5 \mathrm{mV}$.

The $\omega$-conotoxin blockade resembled the condition in which the extracellular $\mathrm{Ca}^{2+}$ concentration was reduced. The recovery of $\omega$-conotoxin inhibition through elevation of the extracellular $\mathrm{Ca}^{2+}$ concentration (Fig. 1A) is consistent with the idea that the target of $\omega$-conotoxin is the $\mathrm{Ca}^{2+}$ channel. In fact, reduction of transmitter release by various inorganic $\mathrm{Ca}^{2+}$ antagonists such as $\mathrm{Mg}^{2+}$ and $\mathrm{Mn}^{2+}$, and several aminoglycoside antibiotics such as streptomycin and neomycin, recovers following elevation of extracellular $\mathrm{Ca}^{2+}{ }^{11), 12)}$

Recent investigations of the effects of various organic $\mathrm{Ca}^{2+}$ antagonists, e.g. verapamil, nifedipine and diltiazem, appear that the pharmacological effects of such drugs on $\mathrm{Ca}^{2+}$ channels have species and tissue selectivity. ${ }^{13)}$ Indeed, D600 and diltiazem block the open state of the ACh-receptor ion channel complex of frog endplate ${ }^{6), 7}$ ) but the effect of D600 on the transmitter release is weak.1) $\omega$-Conotoxin also has high species specificity, blocking neuromuscular transmission in frog and fish, but apparently exerting no effect when intraperitoneally injected into mice. ${ }^{9)}$

There are accumulating evidences that at least 3 types of $\mathrm{Ca}^{2+}$ channels are present in the neuron and other various cells. ${ }^{8)}$ Since binding of $\omega$-conotoxin does not compete with any of the $\mathrm{Ca}^{2+}$ antagonists, Cruz and Olivera ${ }^{2}$ ) proposed that $\omega$-conotoxin defines a new receptor site which affects voltage-dependent $\mathrm{Ca}^{2+}$ channels. In this regard, it is highly probable that $\omega$-conotoxin and the other $\mathrm{Ca}^{2+}$ antagonists bind different types of voltage-dependent $\mathrm{Ca}^{2+}$ channels and this toxin could become a useful tool for the study of differences existing in the voltage-dependent $\mathrm{Ca}^{2+}$ channel in various tissues.

Acknowledgements. The synthetic $\omega$-conotoxin was developed by the collaboration between Peptide Institute, Protein Research Foundation and the organizing group of Special Project Research on Mechanism of Bioelectrical Response, which was supported by a Grant-in-Aid (61107004) from the Japanese Ministry of Education, Science and Culture. 


\section{References}

1) Bregestovski, P. D., Miledi, R., and Parker, I. (1980): Proc. R. Soc. London B, 211, 15-24.

2) Cruz, L. J., and Olivera, B. M. (1986) : J. Biol. Chem., 261, 6230-6233.

3) Hubbard, J. I., Llinás, R., and Quastel, D. M. J. (1969) : Electrophysiological Analysis of Synaptic Transmission. Edward Arnold, London, pp. 133-137.

4) Katz, B., and Miledi, R. (1969) : J. Physiol. (Lond.), 203, 459-487.

5) Kerr, L. M., and Yoshikami, D. (1984): Nature, 308, 282-284.

6) Miledi, R., and Parker, I. (1980) : Proc. R. Soc. Lond. B, 211, 143-150.

7) - (1981): Biomed. Res., 2, 587-589.

8) Nowycky, M. C., Fox, A. P., and Tsien, R. W. (1985): Nature, 316, 440-443.

9) Olivera, B. M. et al. (1984): Biochemistry, 23, 5087-5090.

10) Olivera, B. M. et al. (1985): Science, 230, 1338-1343.

11) Pittinger, C., and Adamson, R. (1972) : Ann. Rev. Pharmacol., 12, 169-184.

12) Rahamimoff, R. (1974): Neurosciences Third Study Program (eds. Schmitt, F. O., and Wordren, F. G.). MIT Press, pp. 943-952.

13) Rahwan, R. G., Piascik, M. F., and Witiak, D. T. (1979) : Can. J. Physiol. Pharmacol., 57, 443-460. 